\title{
Small bowel lymphoma presenting as inguinal hernia: case report and literature review
}

\author{
Michele Teodoro ${ }^{1}$, Maurizio Mannino ${ }^{1}$, Marco Vitale ${ }^{1}$, Edoardo Mattone ${ }^{1}$, Valentina Palumbo ${ }^{1}$, Filippo Fraggetta ${ }^{2}$, \\ Adriana Toro ${ }^{3}$ and Isidoro Di Carlo ${ }^{1 *}$
}

\begin{abstract}
Background: Inguinal hernia is one of the most common benign pathologies that primarily affects men. Primary gastrointestinal non-Hodgkin's lymphoma (PGI NHL) is the most common type of extranodal lymphoma. This study reports a rare case in which these two conditions co-exist.

Case presentation: An 85-year-old male complained of bowel movement pattern change, abdominal distension and loss of weight, without vomiting but with nausea. A computed tomographic scan of the abdomen showed a small bowel obstruction caused by a migration of a small bowel loop in the right inguinal canal, with a clinically non-reducible inguinal hernia. The patient underwent surgery. The histopathological report showed small bowel large B cell non-Hodgkin's lymphoma.

Conclusion: When the diagnosis of the contents of an inguinal hernia is not well-established, surgery should be performed as soon as possible to ensure the cure of the disease and the correct diagnosis of the contents.
\end{abstract}

Keywords: Bowel, Lymphoma, Inguinal, Hernia

\section{Background}

Inguinal hernia is one of the most common benign pathologies that primarily affects men; surgical hernia repair procedures account for approximately 2 million surgical cases annually worldwide, with 850,000 of those performed in the USA [1].

The small bowel [2] is the second leading site, after the stomach [3], for primary gastrointestinal nonHodgkin's lymphoma (PGI NHL). It commonly causes abdominal pain, changes in bowel habits, weight loss, a palpable abdominal mass and blood in the stool [4]. The most common histological subtype of PGI NHL is diffuse large B cell lymphoma, for which systemic chemotherapy with rituximab is the most common treatment [3].

Here, we report a rare case in which these two conditions co-exist and their treatment.

\footnotetext{
* Correspondence: idicarlo@unict.it

${ }^{1}$ Department of Medical, Surgical Sciences and Advanced Technologies "G.F. Ingrassia," Cannizzaro Hospital, University of Catania, Via Messina 829, 95126 Catania, Italy

Full list of author information is available at the end of the article
}

\section{Case presentation}

An 85-year-old male was admitted to the hospital complaining of an approximate 1 month of bowel movement pattern change, abdominal distension and loss of weight, without vomiting but with nausea. Clinical examination revealed abdominal distension (Fig. $1 \mathrm{~A}$ ) and diffuse tenderness without signs of peritonitis. The patient had no lymphadenopathy, his pulse rate was 85 beats/min and his blood pressure was $105 / 60 \mathrm{~mm} / \mathrm{Hg}$. There was a large, painful and non-reducible swelling in the right inguinoscrotal region that was firm in consistency (Fig. $1 \mathrm{~B}$ ). His total WBC count was $13.900 / \mathrm{mm}^{3}$, and his neutrophil count was $96.9 \%$. A computed tomographic scan of the abdomen showed a small bowel obstruction caused by a migration of a small bowel loop in the right inguinal canal, with fullthickness expansion of the bowel wall (Fig. 2). The patient was taken to the operating room for surgery, and because the CT scan showed a mass firmly adherent to the inguinal canal, an abdominal approach was chosen for the possibility of an ileal resection.

(c) The Author(s). 2018 Open Access This article is distributed under the terms of the Creative Commons Attribution 4.0 International License (http://creativecommons.org/licenses/by/4.0/), which permits unrestricted use, distribution, and reproduction in any medium, provided you give appropriate credit to the original author(s) and the source, provide a link to the Creative Commons license, and indicate if changes were made. The Creative Commons Public Domain Dedication waiver (http://creativecommons.org/publicdomain/zero/1.0/) applies to the data made available in this article, unless otherwise stated. 


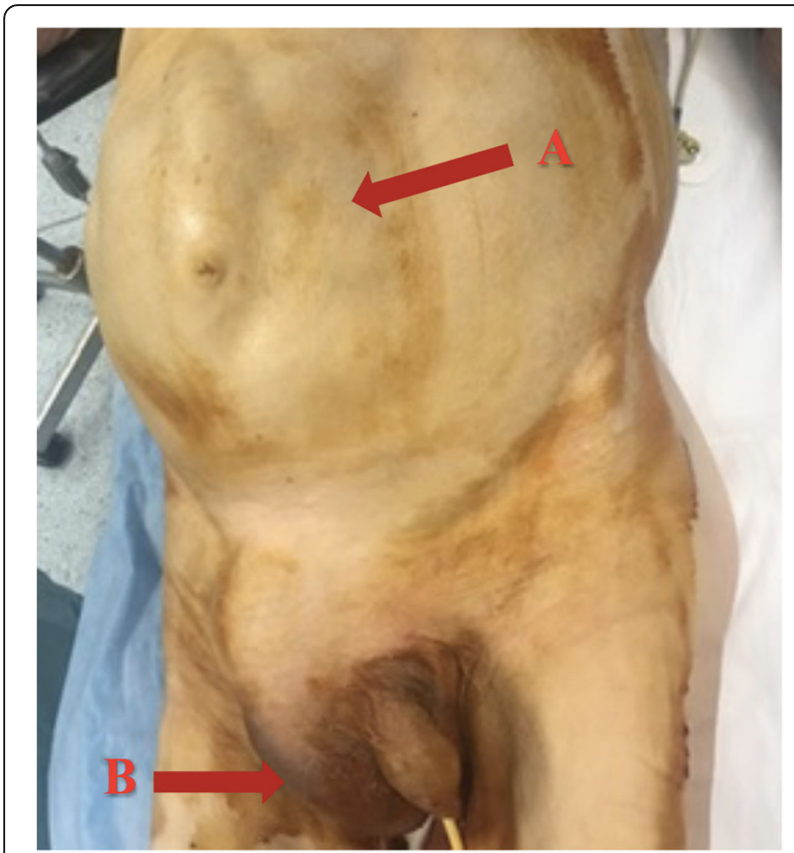

Fig. $1 \mathrm{~A}$ : abdominal distension with a marked loop under the wall. B: giant scrotal mass located on the right side. Non-reducible

On exploration, fluid was found in the peritoneal cavity, and the ileal loop was lodged within the interior inguinal ring. A combined inguinal approach was deemed necessary. On exploration, a small bowel mass firmly adherent to and inseparable from the testicle was found. A bowel resection including the mass and the testicle was performed (Fig. 3). An ileo-ileal latero-lateral anastomosis was performed. Then, a Shouldice herniorrhaphy was performed. We decided to perform a herniorrhaphy without mesh use to avoid the

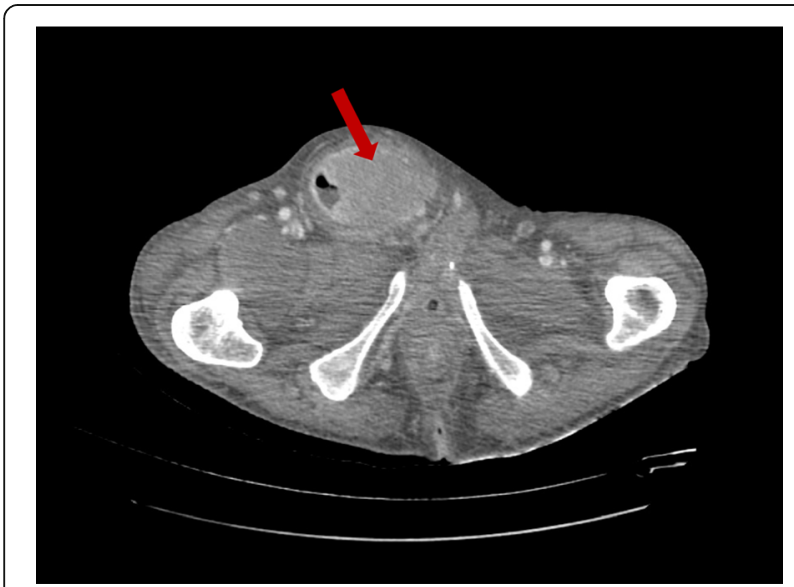

Fig. $2 C T$ scan. The ileal loop located in the inguinal canal judged by the radiologist to be fixed and non-reducible

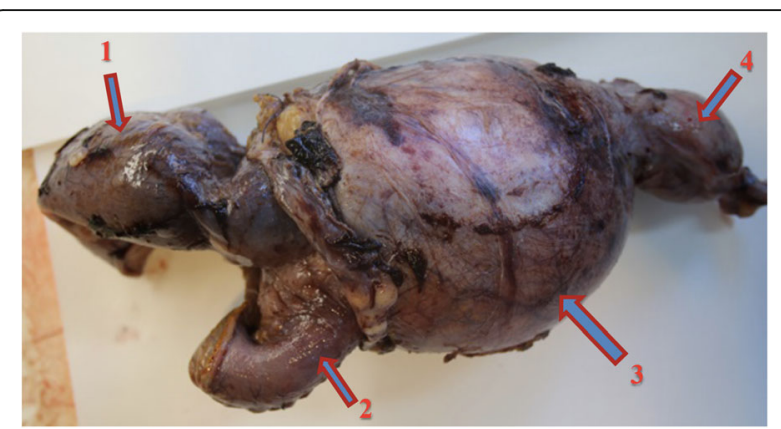

Fig. 3 Specimen. 1: afferent loop, 2: efferent loop, 3: tumour mass, 4: testicle

risk of infectious complications. No complications in the post-operative period were recorded. The histopathological report showed small bowel large B cell non-Hodgkin's lymphoma. The tumour was present up to the submucosa (Figs. 4 and 5). After discharge, the patient was referred to the Haematology Department for further treatment.

\section{Discussion and conclusion}

Approximately, $10 \%$ of inguinal hernias become irreducible; this is often due to benign factors, whereas uncommonly, co-existing malignancy can be the cause of the irreducibility [5].

Malignant masses in inguinal hernias appear in less than $0.5 \%$ of excised sacs [6].

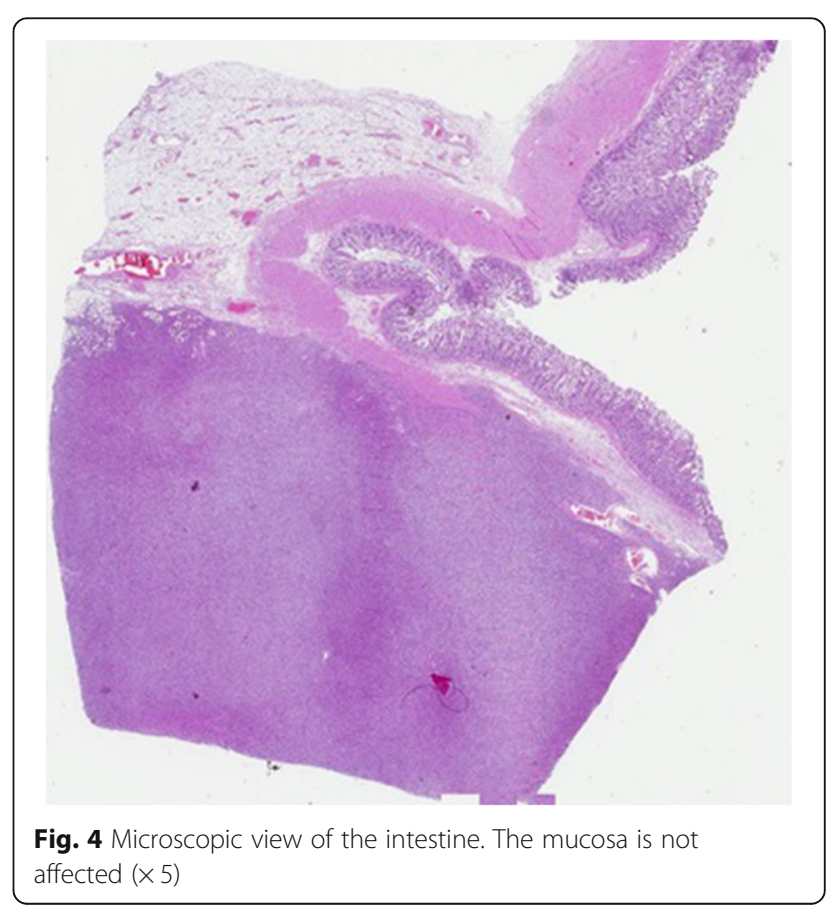



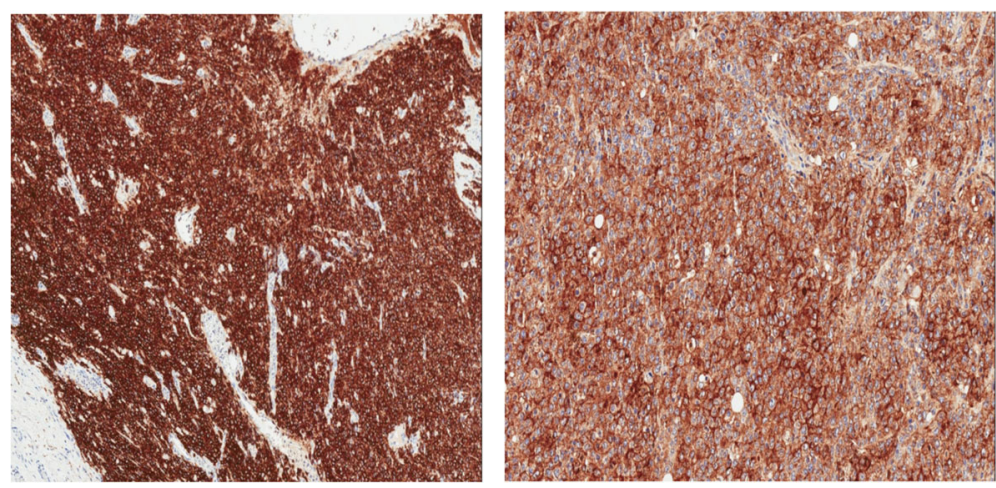

Fig. 5 Positivity for CD30 and CE20 ( $\times 10)$

Tumours in the hernia sac can be classified based on Lejar's studies as saccular and intrasaccular: saccular when they are primary, such as mesothelioma or when metastatic disease involves the peritoneal sac; intrasaccular when the sac contains an organ affected by a malignant tumour [6].

The majority of intrasaccular tumours are of intestinal origin, and the first case that was reported was a sigmoid colon carcinoma [7].

The sigmoid colon is involved in most cases; however, reported cases do not exceed a maximum of four cases per author. The most recent review reported a total of 27 colon carcinoma cases within inguinal hernia sacs and represents most of these patients present in the literature [8].

Other tumours of the intestine are rarely encountered, and they usually originate from the small bowel; eight such tumours have been reported to date [6, 9-15].

Other types of intrasaccular tumours, less frequent than the tumours of intestinal origin, include ovarian and bladder cancer tumours. Ovarian tumours presenting as an inguinal hernia have been described in ten cases, with patients ranging in age from 43 to 81 years [16]. Inguinal hernias containing a tumour of the urinary bladder are very rare, with only 22 cases reported in the literature [17].
Lymphoma diagnosed as an inguinal/femoral hernia is described in a few cases. A review of David R. and colleagues [18] reported 13 cases of lymphoma diagnosed as an inguinal or a femoral hernia, and all these cases originated from the nodes.

Only one case in the literature is reported as small intestine lymphoma diagnosed as a femoral hernia [19], and one case is reported of sigmoid colon lymphoma presenting as an irreducible left-sided inguinal hernia [4]; however, a review of the literature revealed no cases of small intestinal lymphoma presenting as an inguinal hernia (Table 1). This is the first reported case to the best of our knowledge. In our patient, the inguinal approach combined with an abdominal incision was mandatory due to the inability to reduce the hernia. This was probably due to the time lapse of anatomical defect. In fact, the presence of a tumour (in/to the herniated intestine), slowly but progressively increasing in size, does not permit the reduction of the herniated sac in the abdomen. Furthermore, this condition caused strong adhesions between the intestine loop and the sac and between the sac and the testicle. The main difference between this case and a routine case of an inguinal hernia was mainly the inability to manage the sac contents, resulting in a concomitant abdominal approach.

Table 1 Intrasaccular tumours of the inguinal canal, both carcinomas and lymphomas

\begin{tabular}{llll}
\hline Years & Authors & Site of the tumour & Number of cases reported \\
\hline 2008 & Slater [8] & Colon & 27 \\
$2003-2017$ & Different authors [6, 9-15] & Small bowel & 8 \\
2003 & Takeuchi [16] & Ovary & 10 \\
2014 & Katsourakis [17] & Bladder & 22 \\
2010 & Veal [18] & Nodes lymphoma & 13 \\
2009 & Assar [19] & Intestine lymphoma & 1 \\
2017 & Di Carlo present case & Intestine lymphoma & 1 \\
& & Total & 82 \\
\hline
\end{tabular}


In conclusion, this case report suggests that when the diagnosis of the contents of an inguinal hernia is not well established, surgery should be performed as soon as possible to ensure that the disease is cured and that the correct diagnosis of the contents is determined. In cases of a curable tumour, the lapse of time may be detrimental to the patient.

\section{Abbreviations}

PGI NHL: Primary gastrointestinal non-Hodgkin's lymphoma; WBC: White blood cell

\section{Authors' contributions}

TM, MM, PV, ME and VM participated in the care of the patient. TM, MM, PV and TA performed the literature review and drafted the manuscript. FF obtained the pathological data. DCl revised the manuscript. All authors read and approved the final manuscript.

\section{Ethics approval and consent to participate}

Ethical approval for this medical study involving human subjects has respected the Helsinki ethical principles.

\section{Consent for publication}

Consent for publication has been obtained from the patient.

\section{Competing interests}

The authors declare that they have no competing interests.

\section{Publisher's Note}

Springer Nature remains neutral with regard to jurisdictional claims in published maps and institutional affiliations.

\section{Author details}

'Department of Medical, Surgical Sciences and Advanced Technologies "G.F. Ingrassia," Cannizzaro Hospital, University of Catania, Via Messina 829, 95126 Catania, Italy. ${ }^{2}$ Pathology Department, Cannizzaro Hospital, Catania, Italy.

${ }^{3}$ General Surgery, Patti Hospital, Patti, ME, Italy.

Received: 23 November 2017 Accepted: 7 May 2018

Published online: 15 May 2018

\section{References}

1. Murphy JW. Inguinal hernia repair now and in the future. In: Campanelli G. Inguinal Hernia Surgery. Milan: Springer; 2017. p. 37-42.

2. Avcı T, Yabanoğlu H, Arer IM, Koçer NE, Çalışkan K, Börcek P, Ekici Y. Primary small intestinal non-Hodgkin lymphoma diagnosed after emergency surgery. Ulus Travma Acil Cerrahi Derg. 2017;23:128-33.

3. Kagawa T, Kobayashi T, Ueyama S, Okabayashi H, Ogino T, Fujiwara T. Successful management of unresectable small bowel lymphoma with laparoscopy-assisted surgical exclusion of the affected intestine. Asian J Endosc Surg. 2017;10:454-8.

4. Saha TK, Hakim HAN, Banik SK, Haque MR, Chowdhury TN, Talukdaer MT Non Hodgkin's lymphoma in herniated sigmoid colon presenting as irreducible left sided inguinal hernia-a case report and review of literature. J Dhaka Med Coll. 2015;24:73-5.

5. Tan A, Taylor G, Ahmed T. Perforated sigmoid colon carcinoma in an irreducible inguinoscrotal hernia. Ann R Coll Surg Engl. 2013;95:1-2.

6. Zentar A, Tijani T, Elkaoui H, Elghanmi J, Sair K, Taberkant M, Chtata HT. Small bowel schwannoma revealed during an inquinal hernia: a case report. J Med Case Rep. 2014;8:287.

7. Matsumoto $G$, Ise $H$, Inoue $H$, Ogawa H, Suzuki N, Matsuno S. Metastatic colon carcinoma found within an inguinal hernia sac: report of a case. Surg Today. 2000;30:74-7.

8. Slater R, Amatya U, Shorthouse AJ. Colonic carcinoma presenting as strangulated inguinal hernia: report of two cases and review of the literature. Tech Coloproctol. 2008;12:255-8.

9. Ninos A, Douridas G, Liapi G, Ajazi E, lordanou C, Pierrakakis S, Setakis N. Schwannoma in the inguinal canal masquerading an inguinal hernia. Hernia. 2004;8:73-5.
10. Acar T, Güzel K, Aydin R. Leiomyosarcoma of the small intestine found within an inguinal hernia sac: a case report. Acta Chir Belg. 2003;103:336-7.

11. Massani M, Capovilla G, Ruffolo C, Bassi N. Gastrointestinal stromal tumor (GIST) presenting as a strangulated inguinal hernia with small bowel obstruction. BMJ Case Rep. 2017; https://doi.org/10.1136/bcr-2016-217273.

12. Tinoco-González J. Gastrointestinal stromal tumor (GIST) presenting as a groin mass mimicking and incarcerated hernia. Int J Surg Case Rep. 2015;6:166-8.

13. Chan SY, Law WL, Chu KW. Gastrointestinal stromal tumour presenting as incarcerated as inguinal hernia. ANZ J Surg. 2004;74:391-2.

14. Goyal A, Mansel RE, Goyal S. Gastrointestinal stromal tumour in an inguinal hernia sac: an unusual presentation. Postgrad Med J. 2003;79:707-8.

15. Milic DJ, Rajkovic MM, Pejcic VD. Primary omental liposarcoma presenting as an incarcerated inguinal hernia. Hernia. 2005;9:88-9.

16. Takeuchi K, Tsuzuki Y, Ando T, Sekihara M, Hara T, Kori T, Kawakami T, Ohno $Y$, Kuwano H. Malignant mixed mullerian tumor of the ovary growing into an inguinal hernia sac: report of a case. Surg Today. 2003;33:797-800.

17. Katsourakis A, Noussion G, Svoronos C, Alatsakis M, Chatzitheoklitos E. Direct inguinal hernia containing bladder carcinoma: a case report and review of the literature. Int J Surg Case Rep. 2014;5:180-2.

18. Veal DR, Hammill CW, Wong LL. Lymphoma diagnosed at inguinal hernia repair. Hawai Med J. 2010:69:32-4.

19. Assar AN. Primary small intestinal lymphoma presenting as a groin abscess. Saudi J Gastroenterol. 2009:15:64-5.

\section{Ready to submit your research? Choose BMC and benefit from}

- fast, convenient online submission

- thorough peer review by experienced researchers in your field

- rapid publication on acceptance

- support for research data, including large and complex data types

- gold Open Access which fosters wider collaboration and increased citations

- maximum visibility for your research: over 100M website views per year

At BMC, research is always in progress.

Learn more biomedcentral.com/submissions 